\title{
Pedagogical Explorations of an Open- Source Architecture Paradigm in Emerging Design Technologies
}

\author{
KIHONG KU \\ Philadelphia University \\ CHRISTIAN JORDAN \\ Philadelphia University \\ JIM DOERFLER \\ Philadelphia University
}

Open-Source Architecture is an emerging paradigm advocating peer-to-peer collectivity, inclusiveness and participatory culture in architectural design. These conditions support a broad interest at the intersection of education, research and practice in emerging design technologies exploring formal complexity, performance, biomimicry and responsiveness. In the last decade, rich participatory, open-source communities, open-source software, and open-source hardware, created by and designed for the fields of parametric and algorithmic design, visual programming, and physical computing have emerged with resulting opportunities for change in architectural education. We discuss pedagogical approaches that introduce pathways for open-source cultures in architectural design and personal learning networks for professional development.

\section{OPEN SOURCE CONCEPTS}

With the popular trend of individual media creation via Web 2.0 technologies, open source is a term and concept associated with the notion of participatory culture. While this concept was initiated by the software programming community, it has evolved into open source culture, open source hardware, and open content. Wikipedia, Flickr, YouTube, research communities of biotechnology (e.g., BioBricks Foundation) are a few examples (Cheliotis 2009; Ceraso and Pruchnic 2011; Hope 2008; Voyce 2011). Open source is also associated with leveraging voluntary labor in the form of crowdsourcing to outsource portions of a larger task to an indefinite group of volunteers, or 'prosumption' to involve consumers in the production of goods and services or beta testing to enhance usability(Ceraso and Pruchnic 2011). Figure 1 illustrates various open source concepts that have evolved from the initial collaborative software paradigm to other areas with the technological advancements of Web 2.0 platforms and social media, and into a broader open source culture.

\section{OPEN SOURCE PRODUCTION MODES}

Cheliotis (2009) explains the fundamental difference between producing functional and cultural goods. Functional goods such as software programs are typically developed based on a common vision for functionality and involve well-coordinated efforts to facilitate integration and exchange of individual components. In contrast, cultural goods such as music are encouraged to create variations of the same product to appeal to the taste of diverse audiences. Cheliotis (2009) observes that online communities of cultural products adopt loose- or no-coordination strategies compared to the well-coordinated organization of software production. Thus he terms software production modes as branching, merging and forking. This describes how software developers branch some version of source code independently from the core of the software and merge the code back when appropriate. Forking is a variation that happens when one version of a source code is developed into an independent version without merging, when some developers seek to develop new versions because of opinion differences or specific needs. On the other hand, cultural products which are sought for their artistic value adopt $a d-h o c$ and emergent patterns of collaboration. Figure 2 diagrams and compares production modes of software and cultural products. The creation and sharing of cultural products inevitably involve consideration of copyright issues which are traditionally devised to protect the creator. The following section discusses copyright issues that are impacted by open source production.

\section{INTELLECTUAL PROPERTY AND LICENSING}

The history of protecting the copyright of original work in the United States is as old as the country's founding. The Copyright Act of 1790 was focused on the "rights and liberty of printing, reprinting, publishing and vending" while Article I, Section 8, Clause 8 of the United States Constitution grants the power to "promote the progress of science and useful arts" to Congress. A copyright on intellectual property is granted automatically and immediately upon creation of a work. Open source, by its very nature, is created with the intention of becoming part of the public domain. This is where a mechanism for sharing open source content is required, explicitly allowing for open sourcing and third party augmentations. 


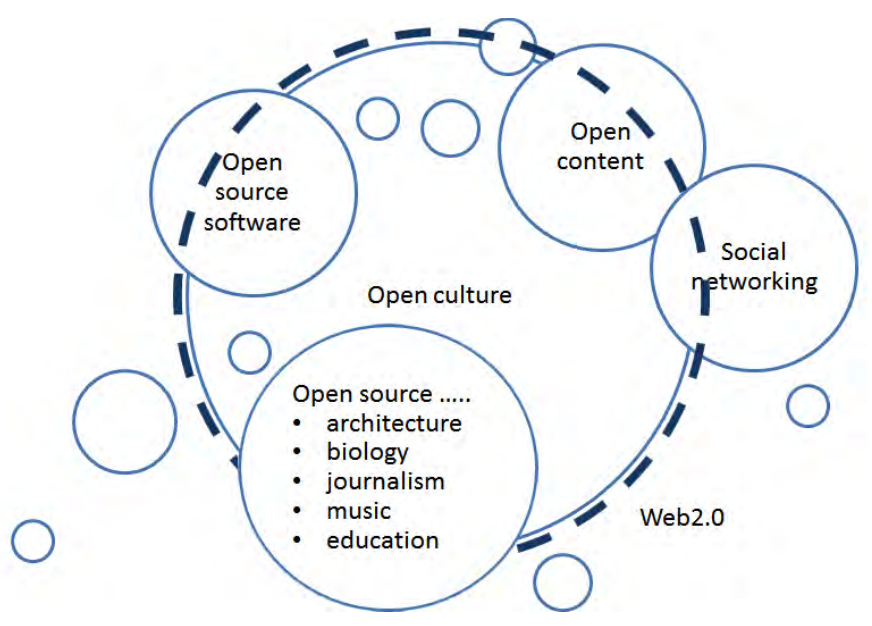

Figure 1. Open Source Concepts.

Before we continue on with the licensing of intellectual property for open source purposes, it is important to discuss why a person or firm would want to participate and contribute within an open source community and why we should feel encouraged revealing our own work and allowing others to augment, revise and manipulate our work. We will discuss the following reasons in the Business Opportunities section later, but it is relevant to mention them here: 1) it has been shown that the work of the contributor to an open source community will benefit from the exposure and; 2 ) it builds the reputation within the open source community by "producing positive network externalities for the author or inventor" (Cheliotis 2009).

Once a creator has decided to share his or her content as open source, it is important to license the work as intended. Creative Commons (CC) is currently the most substantial avenue for licensing available. A visit to the organization's website (creativecommons.org) will allow a user to utilize the CC License Chooser tool. By answering several questions about the intended use of the content, a three layer CC License is created for use with the work to be shared. The three layers make the $\mathrm{CC}$ License unique by providing 1 ) the legal code, 2) a common deed or "human readable" description, and 3) CC Rights Expression Language (REL) or "machine readable" information that makes the work searchable and indexable by search engines (creativecommons.org 2016).

Using the CC License, an author can choose to share his or her work with or without restrictions. Common restrictions include: not for commercial use, share-alike (copyleft), and without augmentation. Careful consideration of the license by the author will allow the open content to have the most impactful life within an open source community.

\section{OPEN CONTENT IN ARCHITECTURE}

Examples of open content in architecture can range from digital models, computer code, script, audio-visual recordings, architectural or engineering plans, drawings, and specifications. In recent years the broader adoption of parametric modeling, visual scripting, and BIM has been accompanied by the rapid growth of online communities which focus on digital design environments and their user support, component, examples sharing, and learning (e.g., grasshopper3d.com, revitcity.com), or software development (e.g., processing.org, food4rhino.com). Such online communities have become platforms for users to find scripts, add-ons, and software that address commonly needed functionalities, and also direct interfaces for software developers to better understand customer needs. At the same time, many users share original scripted or digital models which offer inspiration to other users who may reuse modeled components, or customize examples for their own purposes. Some websites adopt standard copyright conditions for sharing material on their websites while others are covered under the creative commons license for non-commercial use.

A few architects have manifested open-source strategies (Van den Bergh, 2013). For example, UNStudio launched in 2013 an open source initiative and online platform (i.e., Knowledge Platforms) to disseminate selected topics by the firm's team members. Knowledge is shared in the form of blogs and articles which can be accessed by the general public and be commented on or rated, and shared via social media after registration. The site has a 'MYPLATFORM' function (Figure 3) which allows users to select, organize, and contribute their topics of interest. UNStudio aimed to make this platform a knowledge repository and exchange platform with external collaborators. The intent is to engage with and co-create beyond the office boundary for new directions. The depth and scope of articles varies from short promotional articles to more in-depth research topics related to construction materials, innovative and smart systems, and sustainability. The platform performs as a repository of selected topics, a marketing and dissemination tool, and a community forum with external members. MYPLATFORM is bound by the Creative Commons Attribution-NonCommercial-ShareAlike license ("CC License") which allows free sharing and adaptation of others' work when giving appropriate credit and acknowledging modifications and distributing contributions under the same original license. The work cannot be used for commercial purposes.

Chilean architect Alejandro Aravena advocates open-source strategies for the global affordable housing needs. On his firm Elemental's website (Figure 4), four low-cost housing projects' drawings including site plans, architectural plans, and details, are shared in CAD and PDF file format, to convince developers and government agencies of the viability of proven designs. The architect disclaims legal responsibility of the plans reuse by others and issues the plans as guides to be adapted to meet local building codes and material and construction constraints. The use of the firm brand ELEMENTAL is not allowed.

Within the context of sharing architectural research with the general public, Michael Green Architecture (MGA) released in 2012, a 240-page research report on wooden skyscrapers, including details, sections, cost and reference projects (http://mg-architecture.ca/work/the-case-for-tallwood/). The architect publicly shares this report through the firm's website.

The WikiHouse project (http://www.wikihouse.cc/) by Architecture 00 is an open source initiative that advocates open design with a global community incorporating principles of user driven design, mass customization, digital fabrication, and plug-and-play systems. The backbone of the project is a commons platform (Figure 5) linked with Google Drive which can be accessed after registration to review others' work and to create new projects. The commons is shared under a CC-BY-SA 4.0 (creative commons attribution-sharealike 4.0 international) license which allows free sharing and adapting others' work when giving appropriate credit and acknowledging modifications and 


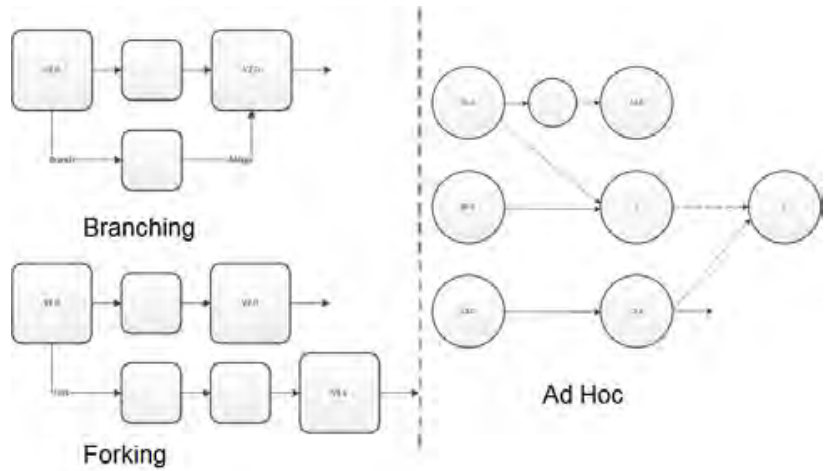

Figure 2. Open source software production (branching, forking) and cultural production (ad-hoc) (adapted from Cheliotis, 2009).

distributing contributions under the same original license. WikiHouse uses a disclaimer that puts responsibility on the user to meet local codes and regulations, to ensure safe use of the information, free sharing of contributions, compliance with the creative commons license, and restriction of use of the WikiHouse logo.

Opendesk.cc (https://www.opendesk.cc/) is a furniture design collaborative that connects designers, manufacturers and customers. The designs are prepared for CNC fabrication. Designers can choose to open source their designs or sell proprietary licenses via Opendesk. Users can either download for free complete design d ocumentation(cut sheet files in Autodesk dxf file format, PDF assembly instructions, CC license text file) to non-commercially manufacture themselves, or purchase through a local registered professional maker on the Opendesk network.

The examples discussed above can be classified based on the type of content (i.e., script, digital model, drawings and plans, technical report, marketing material) and whether the product is shared with the intent for collaborative peer production or one-way dissemination (Table 1). Sharing digital models, code, script, or CAD files allow copying, modification of the designs while technical reports include sufficient details about specific building technologies. It is notable that original plans or technical reports are published for others to use at their own responsibility. Material that includes photos, diagrams, and textual information but not enough specifics can be classified as marketing material.

Table 1. Categorization of open source examples in architecture by content and mode of sharing

\begin{tabular}{|l|l|l|}
\hline & $\begin{array}{l}\text { ONE-WAY } \\
\text { DISSEMINATION }\end{array}$ & $\begin{array}{l}\text { COLLABORATIVE } \\
\text { PEER PRODUCTION }\end{array}$ \\
\hline Digital models, script & & $\begin{array}{l}\text { grasshopper3d.com, } \\
\text { revitcity.com } \\
\text { processing.org, } \\
\text { openprocesing.org } \\
\text { WikiHouse, Opendesk }\end{array}$ \\
\hline $\begin{array}{l}\text { Drawing, plans (CAD } \\
\text { files) }\end{array}$ & ELEMENTAL & WikiHouse, Opendesk \\
\hline Technical report & MGA & UNStudio \\
\hline Marketing material & UNStudio & UNStudio \\
\hline
\end{tabular}

The examples can also be categorized by the type of online platforms (i.e., website vs. collaborative platform) and the type of licensing agreements they utilize (Table 2).

Table 2. Categorization of open source examples in architecture by online platform and licensing

\begin{tabular}{|l|l|l|}
\hline & $\begin{array}{l}\text { TRADITIONAL } \\
\text { WEBSITE }\end{array}$ & $\begin{array}{l}\text { COLLABORATIVE } \\
\text { PLATFORM }\end{array}$ \\
\hline $\begin{array}{l}\text { Custom } \\
\text { disclaimer }\end{array}$ & ELEMENTAL, MGA & $\begin{array}{l}\text { grasshopper3d.com revitcity. } \\
\text { com }\end{array}$ \\
\hline $\begin{array}{l}\text { CC License } \\
\text { (Creative } \\
\text { Commons) }\end{array}$ & & $\begin{array}{l}\text { UNStudio, WikiHouse, } \\
\text { opendesk, processing.org, } \\
\text { openprocesing.org }\end{array}$ \\
\hline
\end{tabular}

\section{PEDAGOGICAL EXPLORATIONS IN THE DIGITAL DESIGN METHODS STUDIO}

Evolving open source tools and communities are relevant to academia and practice on multiple levels, regarding design scholarship, digital design skills and tools. To examine the implications of the open source paradigm, we asked the following questions:

- What are the connections between academic scholarship and open source practices?

- What are the related research skills and information literacy requirements for students?

- What open source strategies can be incorporated into the studio?

- What online platforms are applicable to the design studio?

\section{OPEN SOURCE AND SCHOLARSHIP}

Academic research, teaching, and engagement, are defined within the conventions of scholarship. Research practices require training in research methods that acknowledge existing research and contributions of others, define problems, and apply appropriate research methods. Research findings are published through rigorous peer review processes. Open source scholarship poses questions regarding the norms of academic recognition including intellectual ownership, impact factors, protection of human subjects (i.e., institutional review board (IRB) protocols). On the other hand, teaching material including syllabus and assignments are typically the property of the instructor's university and be subject to restrictions of sharing openly. Despite such barriers, some academics share whole or parts of their work. Some choose to share independent teaching material via personal blogs, while others share partial course content in terms of partial video recordings via Vimeo, YouTube, or course material (e.g., course syllabi, assignments, student work) via open courseware (e.g., wikispaces.com, personal blogs, Wordpress).

\section{RESEARCH SKILLS AND INFORMATION LITERACY IN THE DIGITAL DESIGN METHODS STUDIO}

Incorporating open source content into the classroom requires students to acquire information literacy skills as content users and contributors. The authors found needs in teaching digital design methods incorporating various digital technologies and methods. While students learn relevant digital 
uns Research $\approx$ UNStudio

$\leftarrow \rightarrow$ C $\square$ www.unstudio.com/research

Uns

AMSTERDAM

5HANGHAI

HONG KONG PROJECTS STUDIO RESEARCH NEWS MEDIA CONTACT Search

Uns

unstruolo

INEETINE

MATERIALS

PLATFORM

IMP - WHAT WE DO / WHO

WE ARE

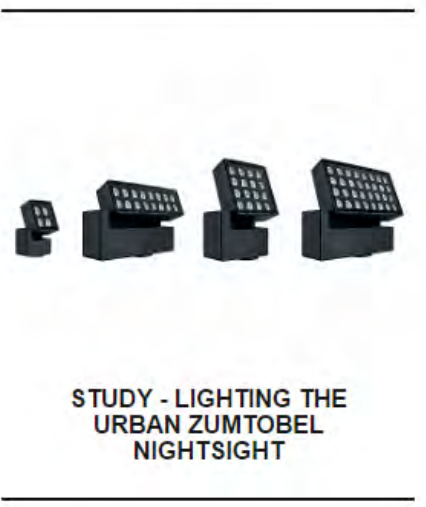

Figure 3. UNStudio Knowledge Platforms.

(Source: http://www.unstudio.com/research)

skillsets in support courses, applying those skills on design studio projects often requires advanced skillsets which are not completely achieved in the classroom. In such cases various open online content including tutorials, classroom recordings, examples and Q\&A information can be helpful. Open source information literacy starts with the ability to find appropriate sources and evaluating the best sources among the vast material that is accessible.

After being able to identify the right information, students need to apply and refine the information for their own purposes. If the content is an open source digital model or code that can be modified, customized to a student's project, the student and instructor need to determine whether it is acceptable to reuse the content as part of the student's own project, and acknowledge copyright and licensing agreements embedded in the content. After gaining confidence with using open content, students may also be tasked to become contributors of open content that can be accessed and used by external communities. Algorithmic designs are procedural content where the coding or scripting is as important as the resulting model or image. Many examples of such content can be found on various computational design blogs, forums, and course websites. In architectural robotics projects, the use of microcontrollers with real-time sensing and actuating devices, involves algorithms and physical prototypes, which can be replicated if the algorithms, electric circuits, fabrication instructions, digital source files, and assembly and operation instructions are shared. Such examples can be found on DIY communities such as the instructables.com website.

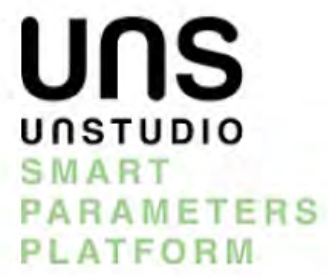

SPP - WHAT WE DO / WHO WE ARE

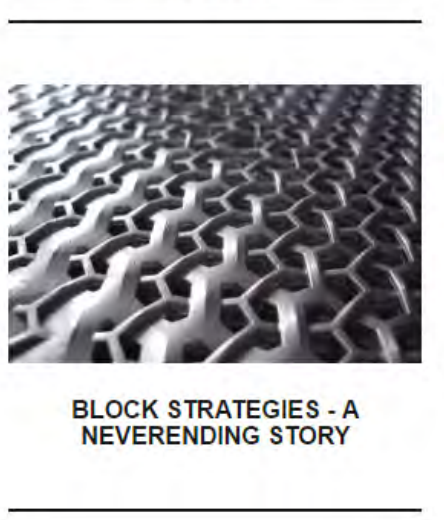

UnS UNSTUDIO ARCHITECTUAAL SUSTAINABILITY PLATFORM

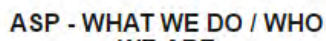
WE ARE

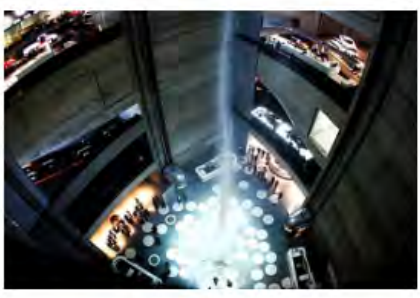

MISSION SUSTAINABLE PART 3 - ASP BOOKLET

\section{OPEN SOURCE PLATFORMS FOR DIGITAL DESIGN AND PROTOTYPING}

The authors have used the Arduino microcontroller, open source hardware, and Processing, an open source software interface, Firefly-a Rhino/ Grasshopper visual programming interface for the Arduino, Rhino3D (proprietary software) , Grasshopper and other add-on software for simulation purposes (e.g., Karamba3d, Weaverbird, Galapagos, Octopus, etc.). In the context of the authors' own design explorations and teaching of responsive design studios, open source has proved to be helpful for learning, reusing and customizing common library objects. Subsequently, code, component models, and lessons learned from these earlier classes have been provided to students of future studios.

\section{OPEN DESIGN COMMUNITY PLATFORM}

While we observed a large number of open source websites, the authors utilized the university Blackboard courseware and the university internal network server for sharing and posting information, data, document, code, and file sharing. The Blackboard courseware facilitates user content sharing via discussion forums for reading discussions, blogging for seminar and research topic sharing. In parallel, the university server proved to be effective for students posting and sharing source files, digital models of ongoing design work, codes, and all relevant design content. When using the network server it is suggested to provide folder templates and file templates for the students to be followed. 


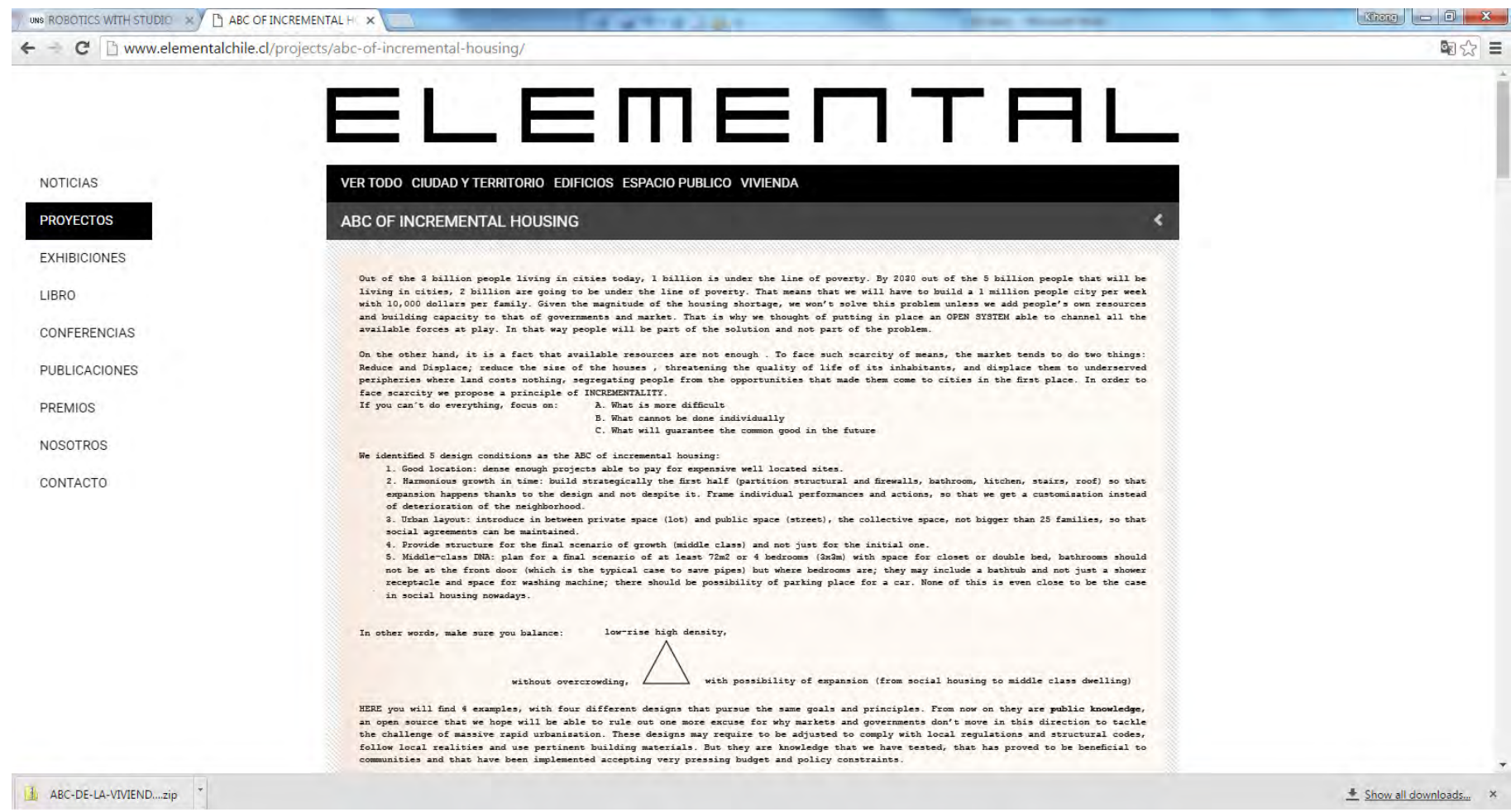

Figure 4. Alejandro Aravena's ABC of Incremental Housing (Source: $\underline{\text { http://www.elementalchile.cl/projects/abc-of-incremental-housing/) }}$

\section{OPEN SOURCES FOR DIGITAL DESIGN METHODS}

The incredible growth of online communities, digital tool tutorial repositories; prove the growing adoption of emerging design technologies by architects. In Table 3, we collected a few examples of (1) online communities that facilitate open information and knowledge sharing; (2) open courseware; (3) tutorial repositories; (4) personal blogs; (5) academic or training providers; and (6) material suppliers and vendors. Within the category of online communities, based on the member types, we included developer-user communities which were initiated by developers and then opened to general users; designer-user communities initiated by users to share visual design and source code; (3) commercial provider initiated communities which engage user communities. These communities share knowledge, information, through tutorials or user forums and downloadable code, 3D models and family objects (e.g., RevitCity), and occasionally relevant information such as job postings and relevant news articles.

Some of the key features of vibrant communities include interactive content, forum settings allowing member posts and rankings. Other online sources such as blogs and websites maintained by academic or commercial training providers offer information of personal research and structured content. In the case of commercial providers, free content previews are offered to attract potential customers for additional fee-based offerings.

From an information consumer standpoint, these online sources can be brought into the design and prototyping process in a number of ways: (1) tutorials, references, guides, are useful to study the basics of the software interfaces and fundamentals of code or electronics to get started; (2) designshare communities such as OpenProcessing.org or DIY communities such as Instructables are helpful to inspire users of the creative potential of the tools, and reuse of source code, CAD files, etc.; (3) various forums are generally useful for troubleshooting issues with code/algorithms and circuitry, although when confronted with novel problems, the drawback is that specific problems may not be resolved because of the lack of expertise in the user base or difficulty of finding the expert (Ku and Grinham 2013); (4) code libraries are generally helpful to simplify coding processes or geometric operations that many users may need; (5) material suppliers offer shopping guides of hardware and provide user feedback; and (6) open creative projects can also be customized and built on by others .

As previously discussed, the benefits of sharing work are worth considering for many creators, and what follows is a brief description of a few instances of leveraging those open source benefits for commercial gain. In February 2008, a 24 year old from Mexico City named Rodrigo Medina launched designplaygrounds "an open research design platform" on Google's Blogspot. For two years, Mr. Medina posted open content to the blog sharing everything from his process to original code for digital fabrication of original designs. In 2014, Mr. Medina founded ThinkParametric.com, a paid subscription site providing "Professional training in the leading technologies for the building industry." In six years, Mr. Medina was able to grow a humble open source blog into a viable training site that counts among its clients Snohetta, Grimshaw, Arup, Gensler and AECOM. (www.thinkparametric.com)

Another example is that of Mode Lab, originally founded as Studio Mode in Brooklyn by Ronnie Parsons and Gil Aikos. Studio Mode began as a collection of best practices for parametric and algorithmic design through McNeel's Rhinoceros 3D modeling program. In addition to creating Studio Mode, Mr. Parsons and Mr. Aikos co-authored the openly shared third edition of Foundations: The Grasshopper Primer which is the industry standard for learning the Grasshopper parametric design plug-in for McNeel's Rhinoceros 5. Through the history of reliable, innovative shared content, Mode Lab is now 
recognized as a thought leader in emerging technology in architecture and has been enlisted as a consultant for several large architecture and engineering firms: KPF, Olin, SOM and Arup to name a few. (www.modelab.is)

The final example is how a small architecture firm outside of a major metropolitan area is able to leverage the advantages of social media for its own marketing purposes. PJA Architecture, P.C. is a small architecture firm located outside of Philadelphia, PA. With humble beginnings in 1993, the firm is an established provider of high quality, commercial architecture. The following is a description of how the lean company is leveraging social media to broadcast its message and engage potential clients from the comfort of the office. PJA Architecture has created accounts for Instagram and Twitter. The former serves as a visual catalog of the firm's projects, interests and musings; the latter provides a conduit to the design and development community that otherwise would be inaccessible without a labor intensive marketing drive. By promoting content on social media, PJA is able to identify potential clients based upon project size/scope, location, and design sensibility very quickly. Engaging these contacts on social media affords a company the opportunity to create a relationship, however tenuous, to other people and companies such that an email, phone call or meeting has a shared basis for continued discussion and relationship building.

\section{CONCLUSION}

While open source architecture illustrates some similarities to software and cultural production, there are a number of barriers including liability and copyright issues. The complexity of building technologies, design and construction processes, building permit processes, and size of projects, make it difficult to implement open source architecture. Nonetheless, design technologies draw many parallels to open source production in software and cultural goods, and the impact of open source is most obvious in emerging digital technologies. From a pedagogical standpoint it is important to evaluate the opportunities that are offered, and understand the challenges of literacy skillsets and licensing agreements. The profession should continue to assess the impact on design, and continuing and academic education.

\section{ACKNOWLEDGEMENTS}

Portions of this article were originally published in the proceedings for the Association of Collegiate Schools or Architecture, 2014 International Conference, Open Cities: The New Post-Industrial World Order.

\section{ENDNOTES}

1. Cheliotis, G. (2009) From Open Source to Open Content: Organization, Licensing and Decision Processes in Open Cultural Production, Decision Support Systems, 47, pp. 229-244, Elsevier.

2. Ceraso, A., and Pruchnic, J. (2011) Open source culture and asthetics, Criticism, Summer 2011, Vol. 53, No. 3, pp. 407-438. Wayne State University Press, Detroit, Michigan 48201-1309.

3. Ku, K., Frosten, S., and Grinham, J. (2014), An Open-Source Paradigm in the Responsive Architecture Studio, ACSA International Conference, June 21-23, 2014, Seoul, Korea.

4. Ku, K. and Grinham, J. (2013) 4D Environments and Design: Prototyping Interactive Architecture, ARCC News and Reports, http://arccweb.org/newsletter/category/ newsletters/37-1-spring-2013/ (accessed March 10, 2014).

5. Hope, J. (2008) Open Source Revolution in Biotechnology, Cambridge, MA: Harvard University Press.

6. Van den Bergh, P. (2013). UNStudio Tried Riding the Open Source Wave, but Failed. http://www.failedarchitecture.com/unstudio-tried-riding-the-open-source-wavebut-failed/ (accessed May 1, 2016).

7. Voyce, S. (2011). Toward an open source poetics: Appropriation, collaboration, and the commons, Criticism, Summer 2011, Vol. 53, No. 3, pp. 337-375. Wayne State University Press, Detroit, Michigan 48201-1309. 


\begin{tabular}{|c|c|c|c|}
\hline CATEGORY & NAME & COMPONENTS & PARTICIPANT TYPE \\
\hline \multirow[t]{6}{*}{ Online communities } & Processing.org & $\begin{array}{l}\text { Download } \\
\text { Examples } \\
\text { Tutorials } \\
\text { References } \\
\text { Forum/Support } \\
\text { Shop/Buy }\end{array}$ & $\begin{array}{l}\text { Open source software developer and user } \\
\text { community }\end{array}$ \\
\hline & Openprocessing.org & $\begin{array}{l}\text { Examples } \\
\text { Course examples } \\
\text { Collections } \\
\text { Shop/Buy }\end{array}$ & Open source design share-user community \\
\hline & Arduino.org & $\begin{array}{l}\text { Download } \\
\text { Shop/Buy } \\
\text { Tutorial } \\
\text { Examples } \\
\text { References } \\
\text { Support/Forum } \\
\text { Blog }\end{array}$ & $\begin{array}{l}\text { Open source hardware developer-user } \\
\text { community }\end{array}$ \\
\hline & RevitCity.com & $\begin{array}{l}\text { Forum } \\
\text { Downloads } \\
\text { Gallery } \\
\text { New/Articles } \\
\text { Resources } \\
\text { Jobs } \\
\text { FAQ }\end{array}$ & Commercial software user community \\
\hline & $\begin{array}{l}\text { Designbymany.com } \\
\text { Case Consulting }\end{array}$ & $\begin{array}{l}\text { Community } \\
\text { Consulting }\end{array}$ & $\begin{array}{l}\text { Commercial training provider on various } \\
\text { tools }\end{array}$ \\
\hline & Instructables.com & $\begin{array}{l}\text { Explore } \\
\text { Create } \\
\text { Contests } \\
\text { Forums }\end{array}$ & DIY user community \\
\hline Courseware & $\begin{array}{l}\text { http://www.wikispaces.com/ } \\
\text { https://realtimecities.wikispaces.com/ }\end{array}$ & Online classrooms & Academic classrooms \\
\hline \multirow[t]{3}{*}{ Tutorial repository } & http://digitaltoolbox.info/ & $\begin{array}{l}\text { Tutorials } \\
\text { Workshop recordings }\end{array}$ & $\begin{array}{l}\text { Academic instructor/ } \\
\text { Consultant }\end{array}$ \\
\hline & http://designalyze.com/ & $\begin{array}{l}\text { Tutorials } \\
\text { Workshop recordings }\end{array}$ & $\begin{array}{l}\text { Academic instructor/ } \\
\text { Consultant }\end{array}$ \\
\hline & Designreform.net & Publication/tutorials & \\
\hline \multirow[t]{3}{*}{ Blog } & http://shiffman.net/ & $\begin{array}{l}\text { Books } \\
\text { Teaching } \\
\text { Blog } \\
\text { Download }\end{array}$ & Educational provider on open source tools \\
\hline & http://www.jeremyblum.com/ & $\begin{array}{l}\text { Blog } \\
\text { Tutorials/Books } \\
\text { Portfolio examples }\end{array}$ & $\begin{array}{l}\text { Educational provider on various software/ } \\
\text { hardware tools }\end{array}$ \\
\hline & http://www.plethora-project.com/ & $\begin{array}{l}\text { Video tutorials } \\
\text { Portfolio examples } \\
\text { Blog } \\
\text { Code library }\end{array}$ & $\begin{array}{l}\text { Educational provider on various design } \\
\text { tools }\end{array}$ \\
\hline
\end{tabular}

Table 3. Categories of Open Source Platforms related to Architecture (modified from Ku et al., 2014) 


\begin{tabular}{|c|c|c|c|}
\hline \multirow[t]{5}{*}{ Academic or Training provider } & http://lab.modecollective.nu/ & $\begin{array}{l}\text { Online tutorials } \\
\text { Workshop arrangements }\end{array}$ & $\begin{array}{l}\text { Commercial training provider on various } \\
\text { tools }\end{array}$ \\
\hline & $\begin{array}{l}\text { http://www.fabfoundation.org/fab-labs/ } \\
\text { what-is-a-fab-lab/ }\end{array}$ & $\begin{array}{l}\text { Technical prototyping } \\
\text { platform } \\
\text { Knowledge sharing network }\end{array}$ & $\begin{array}{l}\text { Digital fabrication and computation } \\
\text { platform }\end{array}$ \\
\hline & $\begin{array}{l}\text { http://elsewarecollective.com/teaching/ } \\
\text { studio-air/ } \\
\text { http://elsewarecollective.com/AIR/ } \\
\text { Tutorial\%20Videos/AIR_TutorialVideoList. } \\
\text { pdf }\end{array}$ & $\begin{array}{l}\text { Tutorials } \\
\text { Webinar }\end{array}$ & Academic instructor \\
\hline & http://www.nycctfab.com/ & $\begin{array}{l}\text { Tutorials } \\
\text { Academic courses } \\
\text { Digital fabrication }\end{array}$ & $\begin{array}{l}\text { Academic instructor/ } \\
\text { Training provider }\end{array}$ \\
\hline & https://www.youtube.com/user/nsenske & Course recording & Academic instructor \\
\hline \multirow[t]{2}{*}{ Material vendors } & https://www.sparkfun.com/ & $\begin{array}{l}\text { Products } \\
\text { Blog } \\
\text { Tutorials } \\
\text { Videos } \\
\text { Classes } \\
\text { Support }\end{array}$ & $\begin{array}{l}\text { Commercial electronics supplier with } \\
\text { tutorials and user discussion board and } \\
\text { support }\end{array}$ \\
\hline & http://www.adafruit.com/ & $\begin{array}{l}\text { Shop } \\
\text { Blog } \\
\text { Learn } \\
\text { Forum }\end{array}$ & $\begin{array}{l}\text { Commercial electronics supplier with } \\
\text { tutorials and user discussion board and } \\
\text { support }\end{array}$ \\
\hline
\end{tabular}

Table 3 (continued). Categories of Open Source Platforms related to

Architecture (modified from Ku et al., 2014) 